\title{
STUdy OF ENGINEERING BEHAVIOR OF COAL Mine WASTE GENERATED FROM BARAPUKURIA COAL MINE AS RoAD SUBGRADE
}

\author{
M. B. Hossain ${ }^{1}$, M. Kumruzzaman ${ }^{2}$ and M. Roknuzzaman ${ }^{3}$ \\ ${ }^{1,3}$ Department of Civil Engineering, Hajee Mohammad Danesh Science and Technology, Dinajpur, Bangladesh \\ ${ }^{2}$ Department of Civil Engineering, Rajshahi University of Engineering and Technology, Rajshahi, Bangladesh
}

Date received: 31/03/2018, Date accepted: 19/04/2018

Corresponding author's email: mbh.civil@hstu.ac.bd

\begin{abstract}
This study is focused on the possibility of using coal mine wastes as a replacement for conventional road subgrades. Various laboratory tests carried out on fresh coal mine waste collected from Barapukuria Coal Mine (Located at Dinajpur, Bangladesh) showed that, it behaves like low strength soil with $0.71 \%$ CBR and $18.74 \%$ plasticity index which is unsuitable for engineering utilization. Later, fine sand and cement were added with the waste. Three different cement proportion were tested $(5 \%, 8 \%$ and $10 \%$ of total weight) keeping a constant sand proportion ( $20 \%$ of total weight). The unconfined compression strength and CBR value were found to increase greatly. Analyzing the test results, waste mixed with $8 \%$ cement and $20 \%$ sand showing $27.44 \%$ CBR and $9.09 \%$ plasticity index was found to be effective for using as subgrade. Chemical analysis of waste detected the presence of lead as $0.026 \mathrm{ppm}$ which may cause groundwater contamination.
\end{abstract}

Copyright (@) 2018 UNIMAS Publisher. This is an open access article distributed under the Creative Commons Attribution-NonCommercial-ShareAlike 4.0 International License which permits unrestricted use, distribution, and reproduction in any medium, provided the original work is properly cited.

Keywords: Coal mine waste, road subgrade, waste treatment, waste recycling, soil improvement

\subsection{INTRODUCTION}

Coal has been used as an energy resource, primarily burned for the production of electricity and/or heat, and is also used for industrial purposes. To satisfy the increasing demand of coal-based power plants, coal production is increasing day by day. In 2015-16 financial year, the Barapukuria coal mine, Bangladesh produced 1,021,638 metric tons of coal which is 345,863 metric tons more than the production of previous year [1]. As production is being increased, the amount of waste generated from coal mining and processing operation is also increasing alarmingly. At present, most of this waste is disposed at the surface, which inevitably requires excessive planning and control to minimize the environmental impact of mining. It also results in non-productive use of land, air and water pollution, possible failure of waste embankments and the loss of aesthetic value of the land. In the field of civil engineering, use of this waste as filling materials for road subgrade work may be a potential way to minimize the detrimental effects of waste disposal. To evaluate this possibility, various engineering and mechanical properties of waste are to be investigated so as to ensure desired strength and durability.

A significant number of studies and researches were carried out on coal mine waste in the past few years. A recent study showed that that mine waste materials mixed with fly ash can be used in transportation projects bringing some environmental benefits by decreasing energy consumption, raw material use, and greenhouse gas emissions [2]. A study on coal mine refuse sampled at an abandoned mine site in South Dakota concluded that the waste can be used as embankment fill material and can provide limited uses for sub-base applications [3]. Most of the studies indicated that fresh coal mine waste is quite unsuitable for engineering utilization. A study on the behavior of mine waste collected from different coal mines indicated that most of the mine wastes need some treatment such as removal of some fine particles, mixing with some amount of cement or some other binding material so that its strength increases and it does not deteriorate when subjected to wetting and drying cycles [4]. It is also evident that the characteristics of coal mine waste vary for different coal mines. In case of Barapukuria Coal Mine, the only mine that is in operation in Bangladesh, a number of studies carried out to investigate the effect of mining work on 
irrigation and ground water [5,6]. In recent study, the coal mine waste generated from Korkino coal mine, Russia was found to be usable as raw materials of brick [7]. But no such study was made locally or internationally to evaluate the possibility of using coal mine waste generated from Barapukuria mine as an engineering material. This paper presents therefore a well-demanded study of engineering behavior of mine waste collected from Barapukuria Coal Mine and finding out the possibility of using them in road subgrade work.

\subsection{PRESENT PRACTICE OF WASTE MANAGEMENT IN BARAPUKURIA COAL MINE}

In Bangladesh there are several coal mines. Among them, Barapukuria Coal Mine is the only natural coal mine reserve that is in operation. About $4 \%$ of total power supply in Bangladesh is generated from good quality of bituminous coal from this mine. It is located in Chowhati village of Phulbari upazilla, Dinajpur, Bangladesh. This mine was discovered in 1985 and has a total geological reserve of 390 million metric tons of coal. With the information provided by Barapukuria Coal Mining Co. Ltd (BCMCL), the coal production during 2009-2013 was 4063000 metric tons [8]. Huge amount of coal mine refuse is being produced every year with the production of solid coal in Barapukuria coal mine. These wastes are not disposed in an authority controlled safe zone. Also they are not generally used for any engineering purpose. Mostly these wastes are stored as heaps temporarily. Sometimes local people collect the waste and use as a low-performing fuel after drying them. Sometimes these wastes are washed with rainwater making the nearby water-bodies polluted.

\subsection{DESIRABLE PROPERTIES OF FILL MATERIALS FOR ROAD SUBGRADE}

A standard fill material should provide sufficient strength, compaction, density and durability to the structure. The coal mine waste, therefore, should have a good strength. Beside the strength, the fill materials should be well graded; it should have low plasticity index and good compaction parameters.

The technical working group of Local Government Engineering Department (LGED) of Bangladesh has prepared an instruction manual for designing road pavement known as "ROAD PAVEMENT DESIGN MANUAL". This manual gives clear specifications about the basic properties of an improved soil required for road construction which can be applicable for coal mine waste. The upper layer of the embankment whether in cut or fill is termed as subgrade. This manual specifies a plasticity index not more than $10 \%$ for improved soils to be used as road subgrade.

The strength of the subgrade is a basic factor in determining the thickness of pavement and is evaluated by means of CBR tests. Strength of subgrade corresponding to its CBR value specified by LGED is presented in Table 1.

Table 1 Strength of subgrade according to CBR value [9]

\begin{tabular}{cc}
\hline CBR value & Subgrade strength \\
\hline $3 \%$ and less & Poor \\
$3 \%-5 \%$ & Normal \\
$5 \%-15 \%$ & Good \\
\hline
\end{tabular}

The manual specifies that the soil to be used as subgrade should have an expansion ratio less than 1 . Beside this, the relation between unconfined compression strength (UCS) with quality of subgrade is shown in Table 2 [10]. 
Table 2 Relationship between unconfined compressive strength and the quality of the subgrade

\begin{tabular}{cc}
\hline UCS value $(\mathrm{psi})$ & Quality of Subgrade \\
\hline$<3.625$ & Very soft \\
$3.625-7.25$ & Soft \\
$7.25-14.50$ & Medium \\
$14.50-29.00$ & Stiff \\
$29.00-55.10$ & Very stiff \\
$>55.10$ & Hard \\
\hline
\end{tabular}

Beside the engineering properties, the waste should the chemically safe for environment. When it is to be used as road subgrade, it is needed to be cautious so that leaching of toxic elements from waste may not pollute groundwater.

\subsection{METHODOLOGY}

Wastes sludge generated in Barapukuria coal mine are conveyed outside of the mining facility through drains. The sludge is then lifted from drains and accumulated as heaps. Waste samples were collected from such heaps. Samples were taken from a depth of $1 \mathrm{~m}$ from the top surface of the heaps to obtain homogeneous waste mix. To evaluate the possibility of using coal mine waste as a subgrade fill, some of its physical and mechanical properties were determined in laboratory. Following tests were carried out for coal mine waste.

$\begin{array}{ll}\text { i. } & \text { Specific gravity test } \\ \text { ii. } & \text { Grain size Analysis }\end{array}$

a. Sieve Analysis

b. Hydrometer test

iii. Atterberg limit tests

iv. Standard Proctor test

v. Unconfined Compression test

vi. California Bearing Ration test

vii. Chemical Analysis of fresh waste

All the above mentioned tests were carried out for fresh coal mine waste and from the test results it was found that the fresh coal mine waste with a low specific gravity, poor gradation, very high plasticity index, very low unconfined compressive strength and very low CBR value is unsuitable for using as subgrade materials unless it is improved by adding some improving agents. It was then planned to add locally available fine sand and ordinary Portland cement with fresh waste in different proportion. The Atterberg limit tests, Standard proctor test, unconfined compression test and California Bearing Ratio test were carried out for each of the improved waste mix. Improvement of waste was done for three different mixes. The proportion of sand was kept the same ( $20 \%$ of total weight) and the proportion of cement was varied in three mixes $(5 \%, 8 \%$ and $10 \%$ of total weight). The mine waste samples to be tested were designated as Mix A, Mix B, Mix C and Mix D as presented in Table 3.

Table 3 Sample designation for different proportions of additives

\begin{tabular}{cc}
\hline Sample designation & Phase of sample \\
\hline Mix A & Fresh coal mine waste \\
Mix B & $5 \%$ cement $+20 \%$ sand $+75 \%$ waste \\
Mix C & $8 \%$ cement $+20 \%$ sand $+75 \%$ waste \\
Mix D & $10 \%$ cement $+20 \%$ sand $+75 \%$ waste \\
\hline
\end{tabular}

\subsection{RESULTS AND ANALYSIS}

The tests were performed maintaining American Society for Testing and Materials (ASTM) standards. 
Results obtained from different laboratory tests for each of the four types of samples are discussed in this section.

\subsection{TESTS FOR SPECIFIC GRAVITY}

ASTM D 854-00 - Standard test for specific gravity of soil solids by water Pycnometer was applied for the determination of specific gravity of fresh coal mine waste. The value of specific gravity was found to be 2.59. This value lies within the range 2.6 to 2.8 which indicates that the fresh coal mine waste resembles like an inorganic soil [11].

\subsection{GRAIN SIZE ANALYSIS}

ASTM D 422 - Standard test method for particle size analysis of soils was applied for identifying soil type and gradation of fresh coal mine waste. Both sieve analysis and Hydrometer test were carried out. Combining sieve analysis and hydrometer analysis data, a grain size distribution curve is plotted as shown in Figure 1.

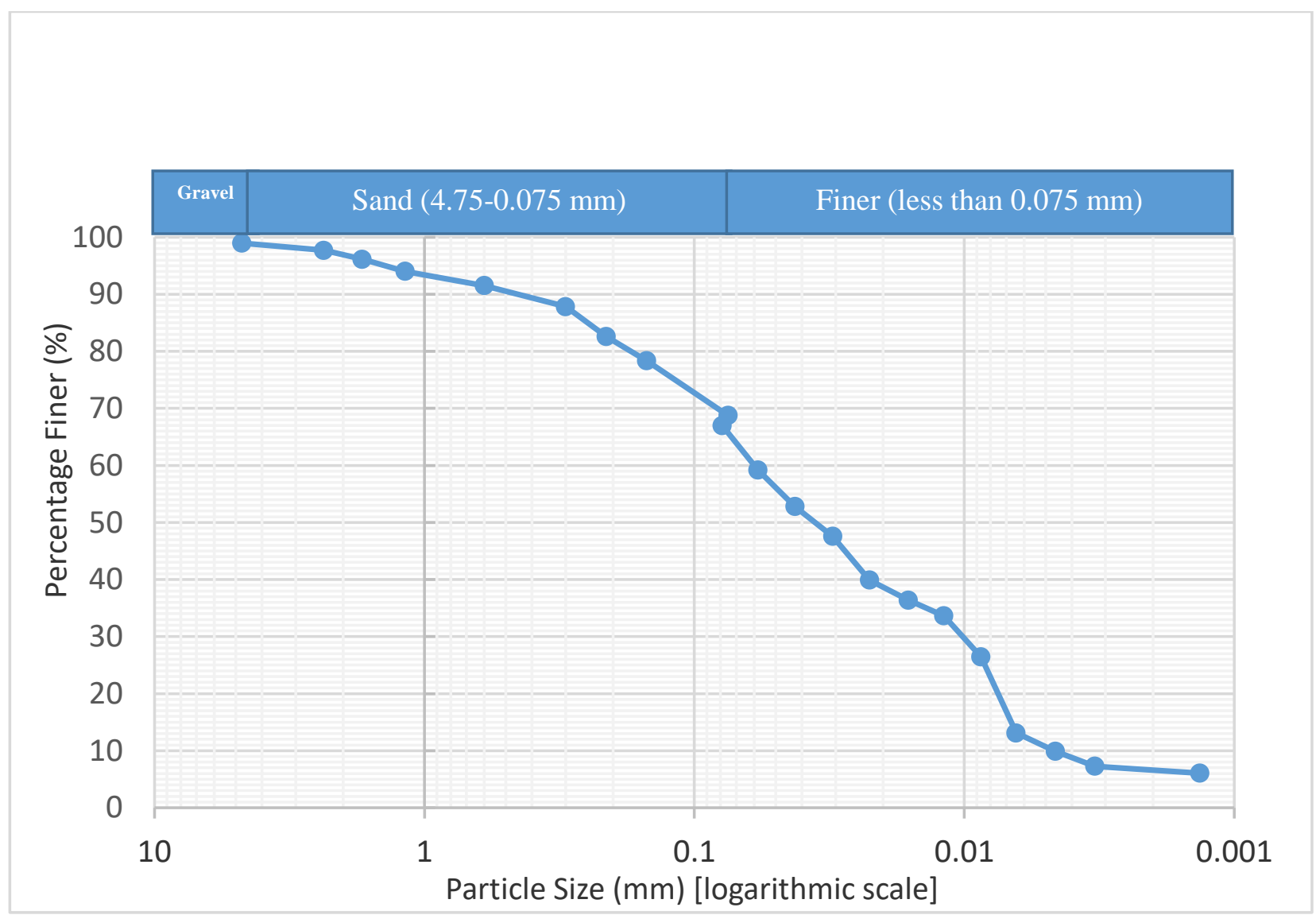

Figure 1 Grain size distribution curve for fresh coal mine waste

Analyzing the grain size distribution curve, the uniformity coefficient $\left(\mathrm{C}_{\mathrm{u}}\right)$ was found to be 13.33 and Coefficient of Curvature $\left(C_{c}\right)$ was found to be 0.37 . A soil sample is said to be well graded if the criteria $\mathrm{C}_{\mathrm{u}} \geq 6$ and $1<\mathrm{C}_{\mathrm{c}}<3$ are satisfied [12]. In case of fresh coal mine waste criteria for $\mathrm{C}_{\mathrm{u}}$ is met, but $\mathrm{C}_{\mathrm{c}}$ lies below unity and hence the soil is poorly graded.

\subsection{ATTERBERG LIMIT TESTS}

ASTM D 4318 - standard test method for liquid limit, plastic limit, and plasticity index of soils was applied for the determination of Atterberg limits of fresh coal mine waste as well as improved coal mine waste 
mixes. Both liquid limit and plastic limit were tested and plasticity indexes were calculated for each of the waste samples. The test results are tabulated in Table 4.

Table 4 Summary of Atterberg limit test results

\begin{tabular}{cccc}
\hline Mix Type & Liquid Limit, LL (\%) & Plastic Limit, PL (\%) & Plasticity Index = LL-PL (\%) \\
\hline Mix A & 32.30 & 13.56 & 18.74 \\
Mix B & 29.82 & 15.32 & 14.50 \\
Mix C & 26.37 & 17.28 & 9.09 \\
Mix D & 23.50 & 19.33 & 4.17 \\
\hline
\end{tabular}

With the increase of cement content the value of Atterberg limits improves gradually as cement adds binding property to the waste. The changes in Atterberg limit for different mixes are shown graphically in Figure 2.

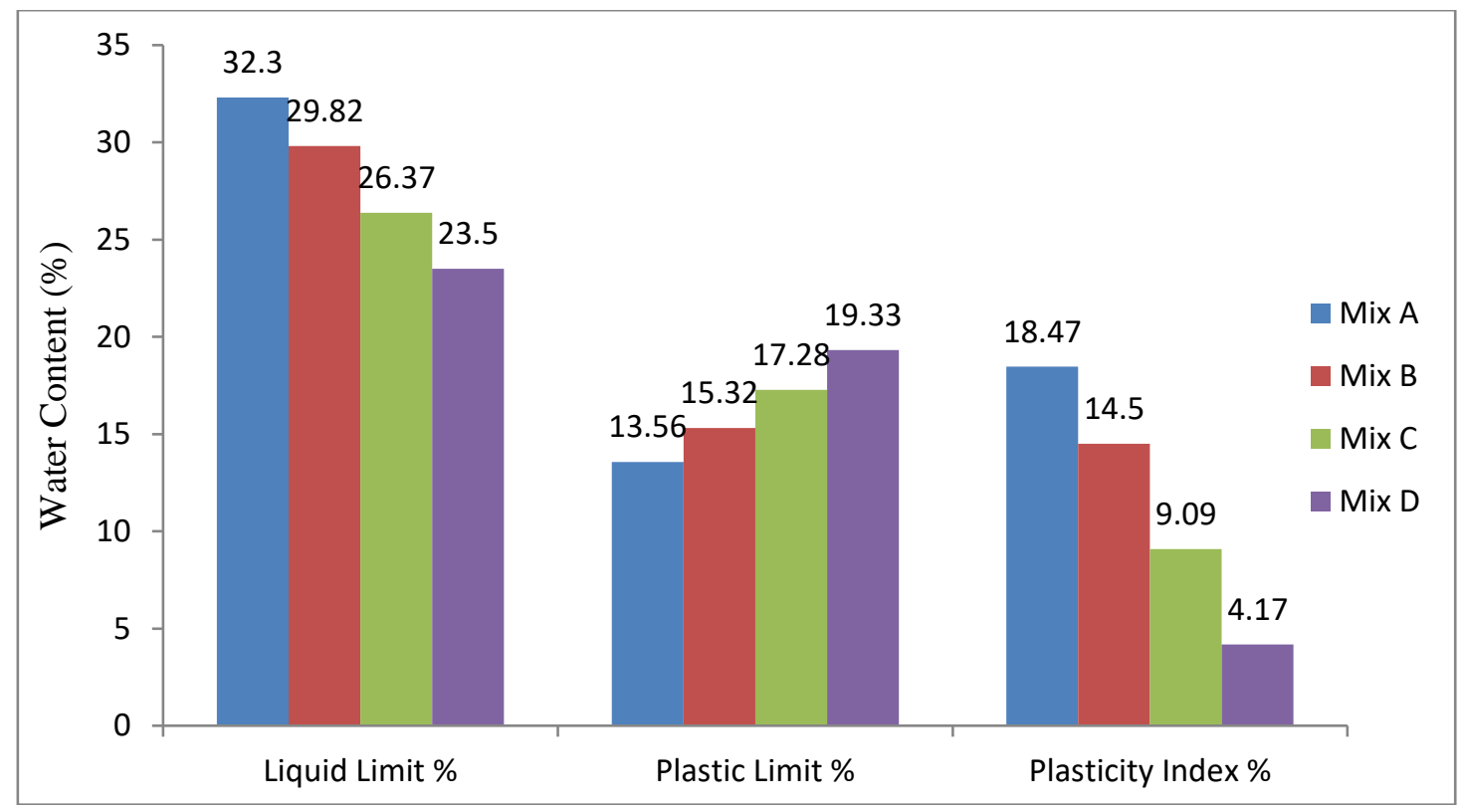

Figure 2 Changes in Atterberg limits for different waste mixes

It can be observed that the plastic limit is increasing whereas liquid limit and plasticity index are decreasing gradually with the increment of cement percentage in coal mine waste sample previously mixed with $20 \%$ sand in each experiment. The Liquid limit and Plasticity index value decreased from $32.3 \%$ (Mix A) to $23.5 \%$ (Mix D) and $18.74 \%$ (Mix A) to $4.17 \%$ (Mix D) respectively mainly due to hydration process. Furthermore, the plastic limit was found to increase from 13.56\% (Mix A) to $19.33 \%$ (Mix D). This is due to the fact that cement chemically reacts with the particles of coal mine wastes which effectively changes the soil grain clay size to silt size [13]. According to "Road Pavement Design Manual1999" when improved or stabilized soil is used as road subgrade, the improved soil having the value of plasticity index (PI) less than 10 will be suitable for road subgrade. The waste Mix B had a plasticity index of $14.50 \%$ which is more that the prescribed limit $10 \%$ and therefore it is quite inferior. But Mix C and Mix D had a plasticity index of $9.09 \%$ and $4.17 \%$ respectively and hence both of them are acceptable.

\subsection{STANDARD PROCTOR TESTS}

ASTM D 698 - Standard test methods for laboratory compaction characteristics of soil using standard effort $\left(12,400 \mathrm{ft}-\mathrm{lbs} / \mathrm{ft}^{3}\right)$ was applied for the determination of optimum moisture content and maximum dry density of each of the waste mixes. The results are summarized in Table 5.

Table 5 Summary of standard proctor test result 


\begin{tabular}{ccc}
\hline Mix type & Optimum moisture content (\%) & Maximum dry density $\left(\mathrm{kN} / \mathrm{m}^{3}\right)$ \\
\hline Mix A & 7.50 & 18.13 \\
Mix B & 10.90 & 16.18 \\
Mix C & 13.20 & 14.56 \\
Mix D & 15.80 & 11.88 \\
\hline
\end{tabular}

The changes in water content and dry density with the variation of cement content are presented in Figure 3.

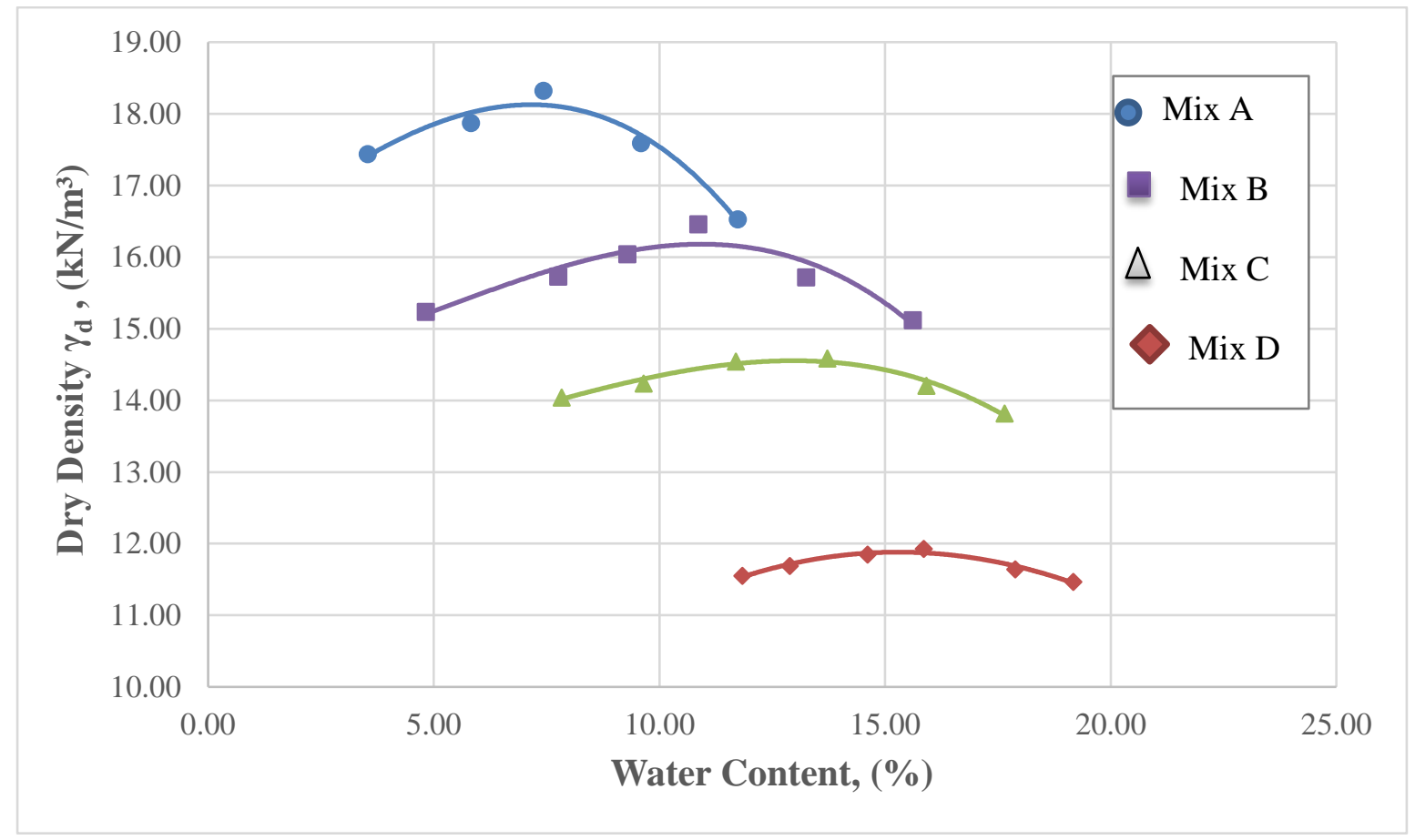

Figure 3 Relationship between dry density and water content for different mixes

The optimum moisture content (OMC) increases from 7.5\% (Mix A) to $15.8 \%$ (Mix D) and the maximum dry density (MDD) decreases slightly from $18.13 \mathrm{kN} / \mathrm{m}^{3}\left(\right.$ Mix A) to $11.88 \mathrm{kN} / \mathrm{m}^{3}(\mathrm{Mix}$ D) as a result of immediate reactions like cation exchange, flocculation, agglomeration and early hydration. This was demonstrated earlier by Kezdi for soils treated by cement [14]. Similar results have been also obtained upon the addition of lime [15].

\subsection{UNCONFINED COMPRESSION TESTS}

ASTM D 2166 - Standard test method for unconfined compressive strength of cohesive soil was adopted for the determination of unconfined compression strength for each of the four mixes. Axial stress versus axial strain curve for different mixes is presented in Figure 4. 


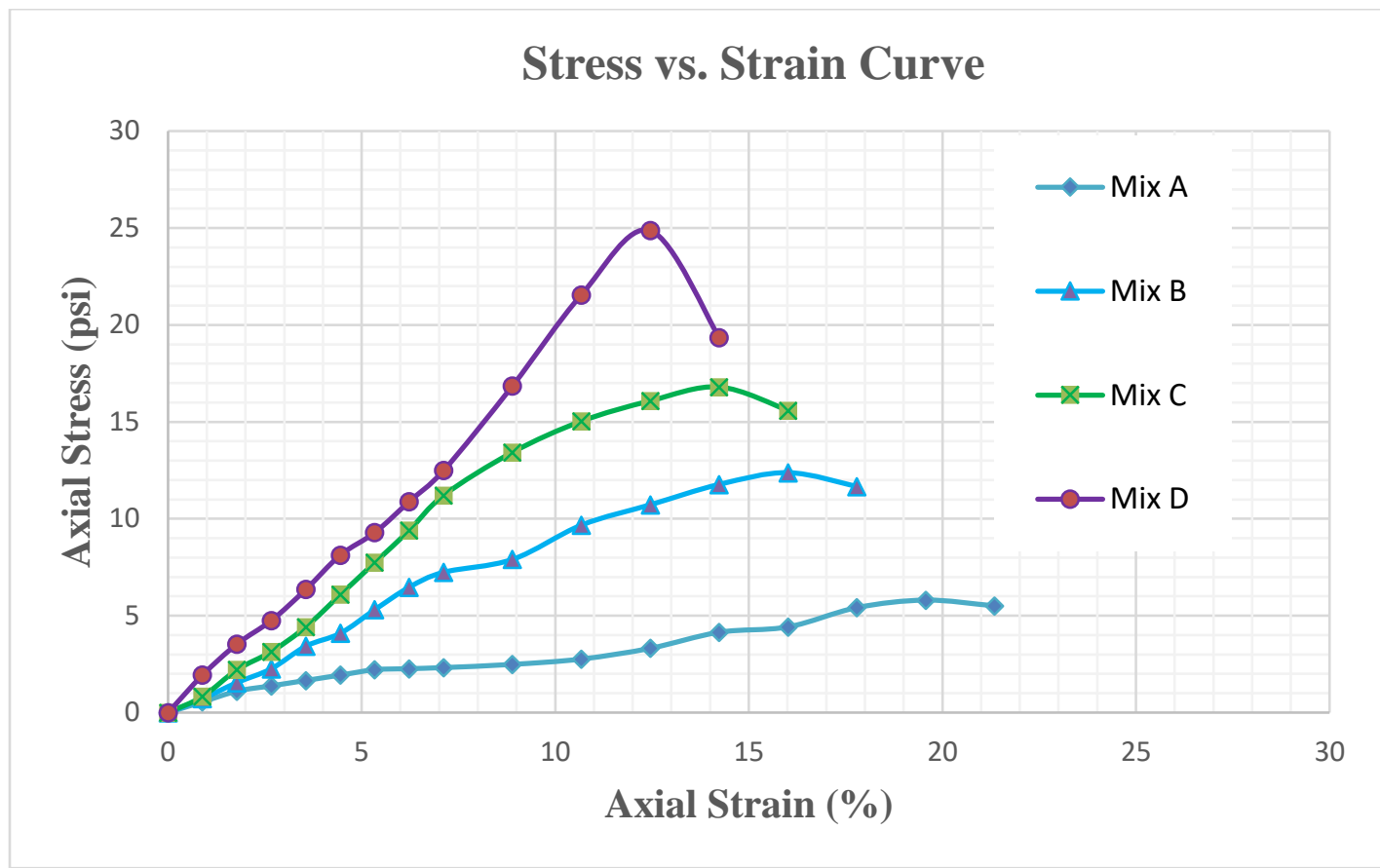

Figure 4 Relationship between axial stress and axial strain for different mixes

A summary of unconfined compression test results is presented in Table 6.

Table 6 Unconfined compression strength of different waste mix.

\begin{tabular}{ccc}
\hline Mix type & Unconfined compressive strength (psi) & $\begin{array}{c}\text { Quality of subgrade } \\
\text { (see Table 2) }\end{array}$ \\
\hline Mix A & 5.80 & Soft \\
Mix B & 12.38 & Medium \\
Mix C & 16.80 & Stiff \\
Mix D & 24.87 & Stiff \\
\hline
\end{tabular}

It can be noted that the fresh coal mine waste has unconfined compressive strength of 5.8 psi only which is in "soft" category in Table 2 and hence cannot be suggested for road subgrade. But all the other three mixes possessed sufficient value of unconfined compressive strength and they are in "Medium" (Mix B) and "Stiff" (Mix C and Mix D) category. Similar research work showed earlier that not only the unconfined compressive strength, but also stiffness and compressibility of the peaty soil were remarkably improved when mixed with cement [16]. The unconfined compressive strength increased from 5.8 psi (Mix A) to 24.87 psi (Mix D). This is an indication that the strength of waste increased remarkably with the addition of sand and cement.

\subsection{CALIFORNIA BEARING RATIO TESTS}

ASTM D 1883 - Standard test method for determination of California bearing ratio of soil was adopted for the determination of CBR value for fresh coalmine waste as well as waste improved with different proportion of additives. Both soaked and un-soaked condition was tested for each sample. Unit load versus penetration curve for different mixes are shown in Figure 5. 


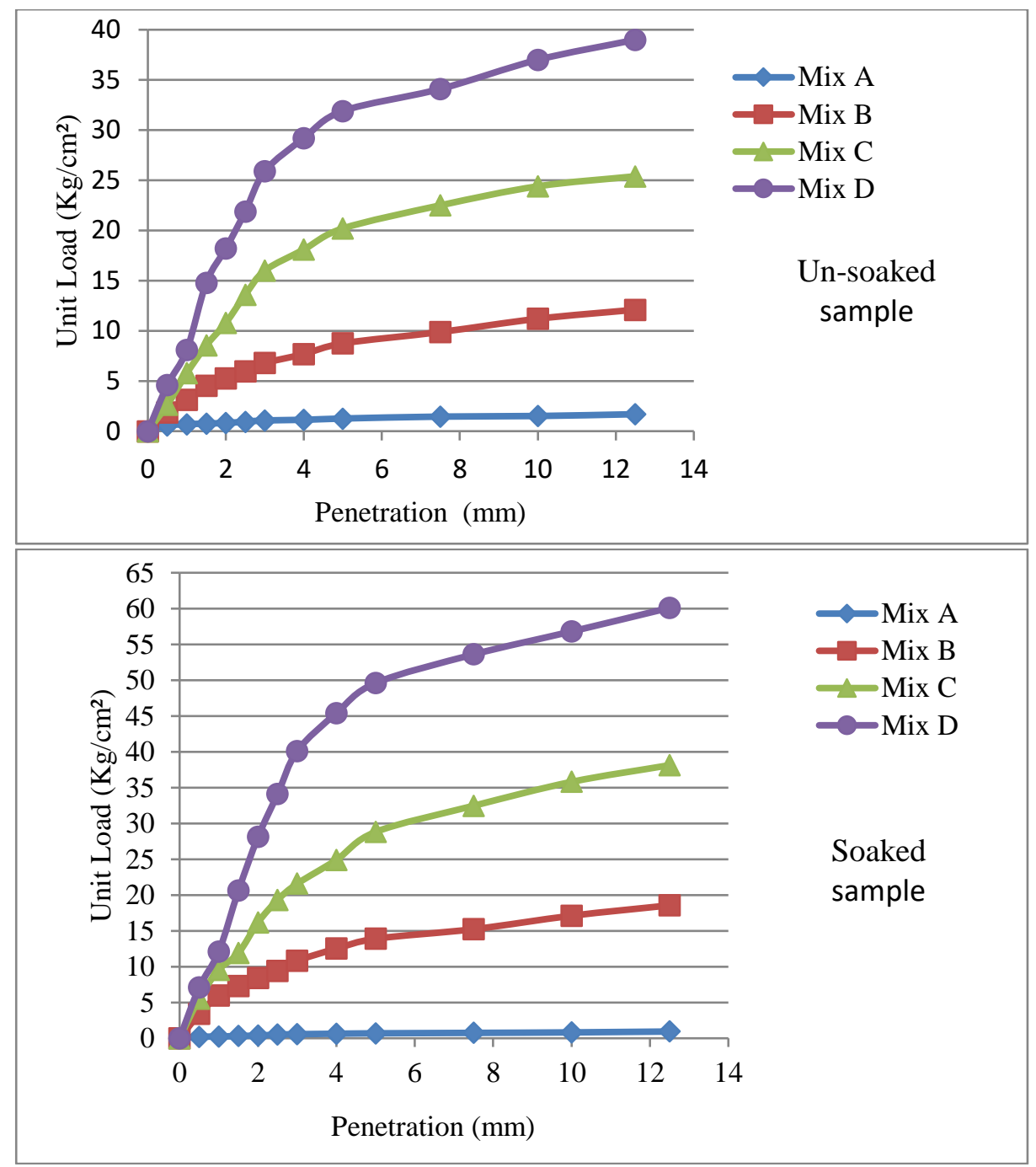

Figure 5 Relationship between unit load and penetration for different mixes

Summary of CBR test result and corresponding expansion ratio are presented in Table 7.

Table 7 CBR values and expansion ratio for different mixes

\begin{tabular}{|c|c|c|c|c|c|c|c|c|c|}
\hline \multirow{2}{*}{\multicolumn{2}{|c|}{ Mix type }} & \multicolumn{2}{|c|}{ A } & \multicolumn{2}{|c|}{ B } & \multicolumn{2}{|c|}{$\mathrm{C}$} & \multicolumn{2}{|c|}{$\mathrm{D}$} \\
\hline & & $2.5 \mathrm{~mm}$ & $5.0 \mathrm{~mm}$ & $2.5 \mathrm{~mm}$ & $5.0 \mathrm{~mm}$ & $2.5 \mathrm{~mm}$ & $5.0 \mathrm{~mm}$ & $2.5 \mathrm{~mm}$ & $5.0 \mathrm{~mm}$ \\
\hline \multirow{2}{*}{ CBR $(\%)$} & Un-soaked & 1.34 & 1.2 & 8.54 & 8.33 & 19.43 & 19.24 & 31.26 & 30.38 \\
\hline & Soaked & 0.71 & 0.66 & 13.39 & 13.24 & 27.59 & 27.44 & 48.71 & 47.23 \\
\hline \multicolumn{2}{|c|}{ Expansion ratio } & \multicolumn{2}{|c|}{1.51} & \multicolumn{2}{|c|}{0.86} & \multicolumn{2}{|c|}{0.54} & \multicolumn{2}{|c|}{0.22} \\
\hline \multicolumn{2}{|c|}{$\begin{array}{l}\text { Subgrade strength } \\
\quad(\text { see Table } 1)\end{array}$} & \multicolumn{2}{|c|}{ Poor } & \multicolumn{2}{|c|}{ Good } & \multicolumn{2}{|c|}{ Good } & \multicolumn{2}{|c|}{ Good } \\
\hline
\end{tabular}

The corresponding graphical representation of variations with incremental cement addition is shown in Figure 6. 


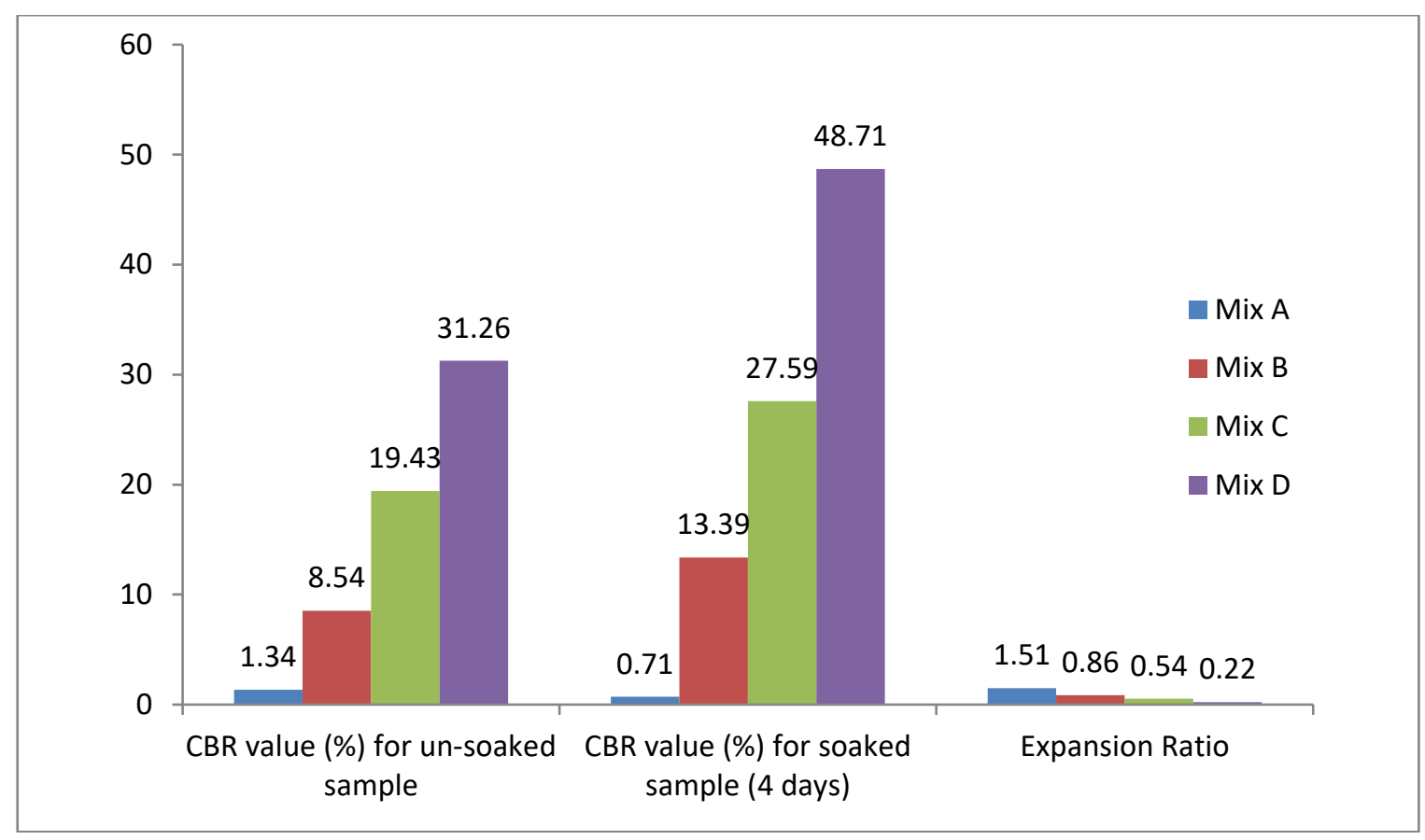

Figure 6 Changes in CBR percentages and expansion ratio with different mixes

It has been observed that, the unsoaked CBR value of fresh coal mine waste is found to be greater than the soaked sample. But this situation was reversed after the addition of cement for Mix B, Mix C, and Mix D. For these three mixes CBR value for soaked condition (96 hours immersed in water) was found to be considerably greater than that of unsoaked condition. This phenomenon happened possibly due to the binding property of cement which was added with coal mine waste along with sand and water. As the samples were immersed for a period of 96 hours in water and the immersing period is more than initial and final setting time of cement, the sample mass was hardened considerably than that of unsoaked condition and hence it possessed comparatively more strength preventing the penetration in CBR test. As a result penetration value was decreased which gave rise to the value of CBR. The CBR value for both soaked and un-soaked condition increased with addition of cement and sand. Un-soaked CBR value increased from $1.34 \%$ (Mix A) to $31.26 \%$ (Mix D) and soaked CBR value increased from $0.71 \%$ (Mix A) to $48.71 \%$ (Mix D). This indicates a prominent improvement in strength of the mixes after improvement. Also the expansion ratio decreases from 1.51 (Mix A) to 0.22 (Mix D) with the incremental addition of cement. These values indicate that the improved coal waste sample have more acceptable values than fresh coal waste sample. Hence, it can be said that the strength of the coal mine waste has been improved.

The fresh coal mine waste (Mix A) showed an expansion ratio is greater than 1. So according to "Road Pavement Design Manual-1999” by LGED Bangladesh, the soil is not suitable for using as subgrade for road construction unless it is improved. After improvement every mix showed an expansion ratio below 1 and hence any of the improved samples is usable as road subgrade. The "Road Pavement Design Manual-1999" also suggests that CBR value in between 3\% to 5\% denotes a subgrade material with normal strength and that in between $5 \%$ to $15 \%$ indicates a subgrade with good strength. Therefore, any of the three improved coal mine waste mixes can be considered as a subgrade with good strength and can be accepted as road subgrade material.

\subsection{CHEMICAL ANALYSIS OF WASTE}

Standard X-ray Fluorescence (XRF) chemical tests were performed on fresh coal mine waste to find-out the existence of possible toxic or harmful content in the sample. An EDF3600B model EDXRF (Energy Dispersive X-ray Fluorescence) spectrometer was used. The test result was obtained by ore work curve method from the attached computer. The test was carried out for three samples of waste and average contents of different elements were calculated. Table 8 is the corresponding results of XRF test. 
Table 8 XRF test result for fresh coal mine waste

\begin{tabular}{ccccc}
\hline Element & $\begin{array}{c}\text { Content in sample-1 } \\
\text { ppm }\end{array}$ & $\begin{array}{c}\text { Content in sample-2 } \\
\text { ppm }\end{array}$ & $\begin{array}{c}\text { Content in sample-3 } \\
\text { ppm }\end{array}$ & $\begin{array}{c}\text { Average content } \\
\text { ppm }\end{array}$ \\
\hline $\mathrm{Al}$ & 1.625 & 1.287 & 1.458 & 1.456 \\
$\mathrm{Si}$ & 5.570 & 4.455 & 4.981 & 5.002 \\
$\mathrm{P}$ & 0.002 & 0.000 & 0.000 & 0.001 \\
$\mathrm{~S}$ & 0.055 & 0.036 & 0.041 & 0.044 \\
$\mathrm{~K}$ & 0.297 & 0.211 & 0.244 & 0.251 \\
$\mathrm{Ca}$ & 0.034 & 0.022 & 0.030 & 0.029 \\
$\mathrm{Ti}$ & 0.081 & 0.087 & 0.067 & 0.078 \\
$\mathrm{Mn}$ & 0.010 & 0.008 & 0.007 & 0.008 \\
$\mathrm{Co}$ & 0.003 & 0.004 & 0.004 & 0.003 \\
$\mathrm{Fe}$ & 2.669 & 2.563 & 2.552 & 2.595 \\
$\mathrm{Cu}$ & 0.011 & 0.011 & 0.011 & 0.011 \\
$\mathrm{Zn}$ & 0.019 & 0.020 & 0.021 & 0.020 \\
$\mathrm{Sn}$ & 0.046 & 0.041 & 0.044 & 0.043 \\
$\mathrm{~Pb}$ & 0.019 & 0.024 & 0.035 & 0.026 \\
$\mathrm{Rb}$ & 0.005 & 0.004 & 0.004 & 0.004 \\
$\mathrm{Nb}$ & 0.001 & 0.005 & 0.001 & 0.002 \\
$\mathrm{Mo}$ & 0.022 & 0.015 & 0.017 & 0.018 \\
\hline
\end{tabular}

The tested lead level of the waste samples is obtained $0.026 \mathrm{ppm}$. No level of lead is considered safe in drinking water; although an action level of $0.015 \mathrm{ppm}$ at the tap can be used to identify highly impacted water. Therefore the lead content of waste may be potentially harmful for ground water, particularly in the areas with high ground water table. The use of coal mine waste as road subgrade in areas with high ground water table should be avoided.

From the laboratory test results discussed in this section, it was evident that fresh coal mine waste (designated as Mix A) is unsuitable for using as road subgrade. Coal mine waste improved with 5\% cement and 20\% sand (designated as Mix B) is also unsuitable as it has plasticity index more than 10 . The other two improved waste mixes, Mix C (8\% cement and 20\% sand) and Mix D (10\% cement and 20\% sand) fulfilled all the requirements for road subgrade and any of them can be suggested for using as road subgrade materials. The Mix C, with lower cement content is therefore, the better choice from economy point of view.

\subsection{CONCLUSIONS}

Improvement of the strength of soil using sand or cement is very common in Bangladesh and other developing countries. The main reason behind using sand or cement is that both Ordinary Portland Cement (OPC) and fine sand are easily available and both are economical under cost consideration. In order to find out the possible way to use coal mine waste in engineering works such as a replacement of road subgrade various necessary parameters are tested and the test result is compared with standard requirement for ideal material. The following conclusions are drawn from the present study:

- The fresh coal mine waste itself has low unconfined compressive strength value of 5.8 psi, high plasticity index of $18.74 \%$ and low CBR value (soaked condition) of $0.71 \%$ which refers to low strength characteristics. It indicates that if the waste is to be used as a fill material it needs some improvement. 
- Using sand and cement as improving agents, unconfined compressive strength increased from 5.8 psi to $24.87 \mathrm{psi}$, plasticity index reduced from $18.74 \%$ to $4.17 \%$ and CBR value (soaked condition) increased up to $48.71 \%$. Which means that the properties of coal mine waste were strengthened as it was being improved.

- The CBR values (soaked condition) for coal mine wastes mixed with $20 \%$ sand and $5 \%, 8 \%, 10 \%$ cement were $13.39 \%, 27.44 \%$ and $48.71 \%$ respectively. Also expansion ratio decreased from 1.51 to 0.22 when coal mine waste sample was mixed with sand and cement which are acceptable. So, the treated sample can be used as road subgrade.

- According to "Road Pavement Design Manual-1999", a good subgrade should have a plasticity index less than $10 \%$ and it should have a CBR value in between 5\% to $15 \%$. From the present study it is observed that all the three mixes satisfies the criteria of CBR but the Mix B having a plasticity index of $14.50 \%$ becomes inferior as the value is more than $10 \%$ whereas the Mix C and Mix D satisfy the criteria of plasticity index. Therefore Mix C and Mix D fulfill both the requirements of plasticity index and CBR. As the mix $\mathrm{C}$ has a lower proportion of cement, it will be economical in cost. Hence the Mix C (coal mine waste improved with $8 \%$ cement and $20 \%$ sand) with a plasticity index of $9.09 \%$ and CBR value of $27.44 \%$ can be accepted as the best choice to use as road subgrade. In many cases of road construction, existing low strength soil subgrade is to be stabilized using cement. In such cases the improved coal mine waste (Mix C) can be used as replacement of existing soil with economy.

- From Chemical analysis it is observed that the collected coal mine waste contains only harmful constituents lead in $0.026 \mathrm{ppm}$. An action level of $0.015 \mathrm{ppm}$ at the tap can be used to identify highly impacted water. Therefore there is a possibility of contaminating ground water by leaching especially in case of areas with high ground water table.

The plasticity index of the recommended Mix C is $9.09 \%$ and it is very closed to the marginal value of $10 \%$, therfore, further research should be done to analyse the variability of plasticity index in several samples of mix C. Furthermore, studies are recommended in this field to find out a more economical way to improve the quality of fresh coal mine waste. Fly ash can be a potential substitute to cement. Also leaching characteristics of waste should be carefully examined in order to prevent possible ground water contamination by lead.

\section{REFERENCES}

[1] BCMCL. (2016). Production Statistics. Accesses 7th September 2016 http://www.bcmcl.org.bd/index.php?page=production_statistics

[2] Gorakhki, Mohammad H., Sultan A. Alhomair, \& Christopher A. Bareither. (2017). Re-Use of Mine Waste Materials Amended with Fly Ash in Transportation Earthworks Projects. Research Report - MPC Publications: MPC-17-332. North Dakota State University - Upper Great Plains Transportation Institute, Fargo: Mountain-Plains Consortium.

[3] Jones, A. L. \& Uckert, R. S. (2006). The investigation of the use of coal mine refuse for sub-base material and embankment fill in south Dakota. BLRS and ASMR, R.I. Barnhisel (ed.) 3134 Montavesta Rd., Lexington, KY 40502. Retrieved from http://www.asmr.us/Portals/0/Documents/Conference-Proceedings/2006-Billings/0317Jones.pdf

[4] Agarwal, V. K. (2009). Geotechnical investigation of coal mine refuse for backfilling in mines. Undergraduate thesis submitted to Department of Mining Engineering National institute of technology, Rourkela - 769008. Retrieved from http://ethesis.nitrkl.ac.in/1348/

[5] Kibria, M. G., Quamruzzaman, C., Ullah, A. S. M. W. \& Kabir, A. K. M. F. (2012). Effect of longwall mining on groundwater forunderground coal extraction in Barapukuria, Bangladesh. Journal of mines, metals \& fuels. 60: 6066.

[6] Howladar, M. F., Deb, P. K., Shahidul, A. T. M. \& Miah, M. (2014). An Assessment of the Underground Roadway Water Quality for Irrigation Use around the Barapukuria Coal Mining Industry, Dinajpur, Bangladesh. Proceeding of the International Conference on Mechanical, Industrial and Energy Engineering 2014, Khulna, Bangladesh.

[7] Stolboushkin, A. Y., Ivanov, A. I. \& Fomina, O. A. (2016). Use of Coal-Mining and Processing Wastes in Production of Bricks and Fuel for Their Burning. Proceeding of the International Conference on Industrial Engineering, ICIE 2016. 1496-1502 
[8] BCMCL. (2009). Progress report on the implementation of various programs and projects (achieved five years) from last January 2009 to December 2013. Retrieved from

http://new.bcmcl.org.bd/index.php?page=download_report

[9] LGED. The Technical Working Group. (1999). Road Pavement Design Manual. Retrieved from http://www.lged.gov.bd/UploadedDocument/UnitPublication/4/99/1999_Road\%20Pavement\%20Design\%20Manua $\underline{1 . p d f}$

[10] Das B. M. (1994). Principles of Geotechnical Engineering. 3rd edition. PWS-Kent Publishing Company, Boston.

[11] Arora K. R. (2006). Soil Mechanics and Foundation Engineering. 6th Edition. Standard Publisher Dist., ISBN: 818014-028-8.

[12] Holtz, R. \& Kovacs, W. (1981). An Introduction to Geotechnical Engineering. Prentice-Hall, Inc. ISBN 0-13484394-0.

[13] Panda, A.P. \& Rao, S.N. (1998). Undrained strength characteristics of an artificially cemented marine clay. Marine georesources \& geotechnology 16: 335-353.

[14] Kezdi, A. (1979). Soil Physics: Selected Topics (Developments in Geotechnical Engineering.). ISBN 0-444-997903.

[15] Dallas N. L. (1995). Handbook for Stabilization of Pavement Subgrade and Base Courses with Lime. ISBN-13: 978-0840396327.

[16] Skels, P., Bondars, K. \& Korjakins, A. (2013). Unconfined compressive strength properties of cement stabilized peat. Proceeding of the 4th International Conference CIVIL ENGINEERING`13 Proceedings Part I Construction And Materials. 202-206. 